\title{
Fluoroquinolone-induced Achilles tendinitis
}

\author{
PK Tam *, Carmen TK Ho
}

\section{A B S T R A C T}

We report a case of Achilles tendinitis after intake of ciprofloxacin for treatment of respiratory tract infection. Fluoroquinolone-induced tendinopathy is an uncommon but increasingly recognised adverse effect of this antibiotic class. Most of the cases occur in the Achilles tendon and may lead to tendon rupture. Possible predisposing risk factors include use of steroid, patients with renal impairment or renal transplant, old age, and being an athlete. The drug should be stopped once this condition is suspected. Symptomatic treatment should be given and orthopaedic referral is desirable if tendon rupture occurs.

\section{Hong Kong Med J 2014;20:545-7}

DOI: $10.12809 / \mathrm{hkmj} 134105$

PK Tam *, MB, BS, FHKAM (Medicine)

CTK Ho, MB, BS, FHKAM (Medicine)

Department of Medicine, Tung Wah Hospital, 12 Po Yan Street, Sheung Wan, Hong Kong

* Corresponding author: alvintam@graduate.hku.hk

\section{Case report}

A 59-year-old woman with good past health, except for post-radioiodine hypothyroidism on T4 replacement, had a 3-week history of cough with yellowish sputum but no fever. She visited a general practitioner and was prescribed a course of ciprofloxacin for possible respiratory tract infection. Three days after starting the drug, she noticed pain and swelling over the left heel. She was not on any other medications including steroid. She went hiking regularly and there was no history of trauma. There was no history of joint or tendon problems. On presentation in May 2012, physical examination revealed tenderness and swelling over the left Achilles tendon (Fig 1). Ultrasound revealed Achilles tendinitis with increased flow on power Doppler signal. There were no signs of tear or calcium deposition (Fig 2). Due to the temporal

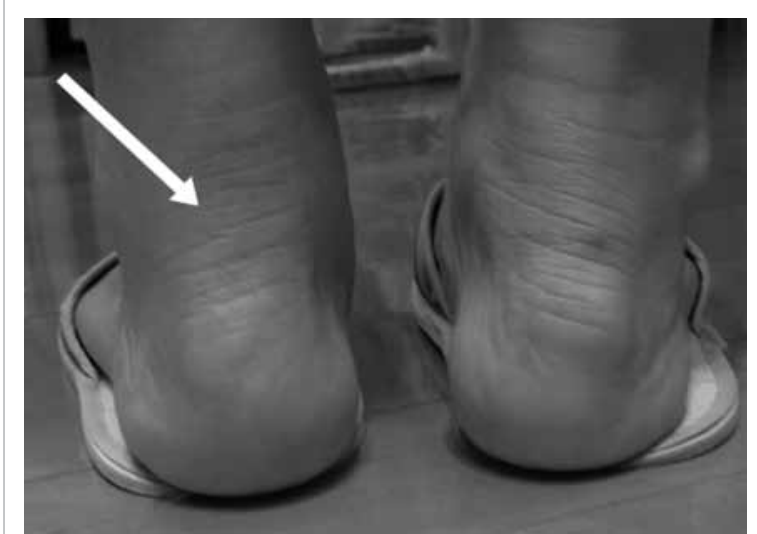

FIG I. Swollen left Achilles tendon (arrow) relationship and the absence of other obvious causes, the diagnosis was ciprofloxacin-induced Achilles tendinitis (the Naranjo Scale was 7 , ie probable adverse drug reaction). ${ }^{1}$ Ciprofloxacin was stopped and the patient was advised to avoid hiking until symptoms subsided completely. She recovered fully 2 weeks later.

\section{Discussion}

Fluoroquinolone-induced tendinopathy was first reported in $1983^{2}$ and, since then, more than 100 cases have been reported in the literature. A case-control study from Italy found that use of fluoroquinolone was associated with higher risk of tendon disorders as well as Achilles tendon rupture (odds ratios, 1.7 and 4.1, respectively) compared with the control population. ${ }^{3}$ Another case-control study done in the United Kingdom estimated the risk to be 3.2 cases

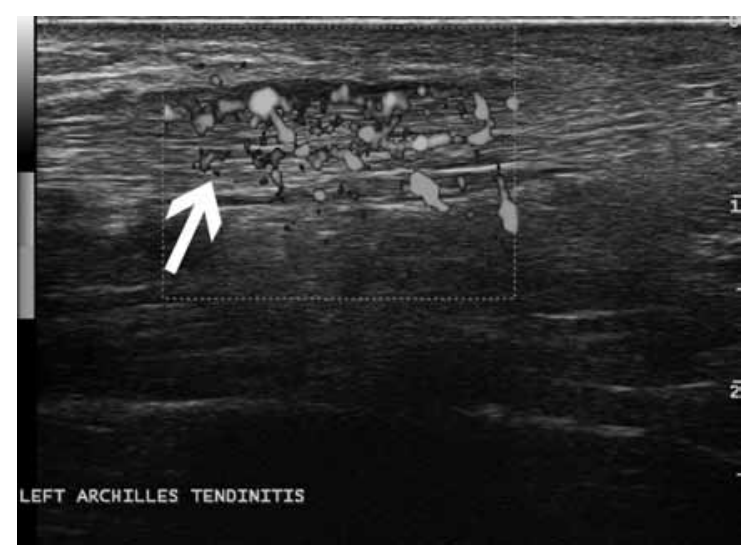

FIG 2. Ultrasound shows thickened Achilles tendon (arrow) with increased flow on colour Doppler examination 


\section{氟化喯諾酮引起的筋腱炎 \\ 譚沛傑、何紫笏}

本文報告一宗以抗生素ciprofloxacin治療呼吸道感染導致阿基里斯筋 腱炎的病例。氟化喹諾酮引起的筋腱炎並不常見, 然而其不良反應卻 日益受到關注。大部份病例影響阿基里斯筋腱, 最嚴重可導致筋腱斷 裂。正在服用類固醇、腎功能不健全、腎移植的病人、老年人和運動 員等有較大機會出現此情況。一旦懷疑病人有此症狀, 必須先停止服 用有關藥物, 然後施以適合的治療來舒緩症狀。若出現筋腱斷裂則應 考慮轉介骨科作治療。
The underlying pathophysiology of the tendinopathy is not entirely known. A number of possible mechanisms have been proposed in animal and in-vitro studies. Ciprofloxacin could affect the metabolism of fibroblasts in tendon structures by reducing collagen synthesis and increasing extracellular matrix degradation. ${ }^{11}$ The chelating property of fluoroquinolones may also disturb the physiological interaction between cells and extracellular matrix. ${ }^{12}$ There was also evidence that fluoroquinolone increased apotosis in human tenocytes. $^{13}$ In renal transplant recipients, the clearance of the drug may be impaired resulting in elevated concentrations in the tendon structures.

per 1000 patient-years. ${ }^{4}$

The commonest fluoroquinolones in the reported cases included ciprofloxacin and pefloxacin but, essentially, all the commonly used fluoroquinolones such as levofloxacin, ofloxacin, and norfloxacin have been associated with this adverse event.

Achilles tendon is the commonest affected site, accounting for nearly $90 \%$ of the reported cases Other tendons like quadriceps tendon, rotator cuff tendon, as well as the site of tendon insertion may also be affected (there were two cases of epicondylitis reported after quinolone use)..$^{5}$ Tendinitis was the commonest pathology, present in $83.7 \%$ of the cases. Tendon rupture occurred in about $40 \%$ of the patients. ${ }^{6}$ A case-control study found that patients taking fluoroquinolones had a 4-fold increased risk of Achilles tendon rupture compared with the general population. ${ }^{3}$ Other complications related to tendinitis, such as carpal tunnel syndrome, are also possible. $^{7}$

The mean time of symptom onset was about 2 weeks after initiation of the culprit medication, although it could range from 2 hours to as long as 6 months and, in $50 \%$ of the cases, it started within 6 days of drug intake. The mean age of affected subjects was 59 years. ${ }^{6}$

Several risk factors have been identified in the development of tendinopathy in patients taking fluoroquinolones. Among them, steroid use was the most significant risk factor. Most of the time, this was related to long-term use of systemic steroids, although even inhaled steroids were thought to be associated with the development of quinoloneinduced tendinopathy. ${ }^{8}$ Other risk factors include old age ( $>60$ years old), haemodialysis, renal impairment, renal transplant recipients, participation in sports activities, and history of rheumatic disorders. ${ }^{6,9}$ One previous review stated that males were more likely to develop this side-effect. ${ }^{6}$ One more recent case-crossover study, however, found that the association of tendinopathy and fluoroquinolone use was stronger in females, although not statistically significant. ${ }^{10}$ Therefore, it is not sure whether a particular gender is more likely to have this problem.
Other risk factors like age, repeated trauma due to sports activities, or steroid therapy may impair the repair process of the tendon, thus, increasing the risk of tendinopathy in this group of patients. ${ }^{6,14}$

The tendinopathy usually presents with acute or subacute onset of pain and swelling over the tendon. Together with a history of recent consumption of fluoroquinolones and absence of other obvious causes of the tendinopathy, the diagnosis can be established. Imaging like ultrasound or magnetic resonance imaging is not mandatory but can aid in diagnosis, especially for visualising deep structures. Typical ultrasound findings of tendinopathy include thickened tendon with increased flow on colour Doppler examination.

The most important step in management is to stop the culprit drug. Appropriate rest and pain control are important. Pain can be well-controlled by non-steroidal anti-inflammatory agents; nonpharmacological treatments include ice therapy and therapeutic ultrasound. In case of tendon rupture, early referral to orthopaedic surgeon is desirable. Treatment options include immobilisation with

Prevention is also very important. One should only use fluoroquinolones when really necessary. Our patient's symptoms did not suggest genuine lower respiratory tract infection; therefore, prescription of antibiotics was indeed not indicated. Moreover, quinolone is not the recommended first-line empirical antibiotic for treatment of chest infection in Hong Kong (it should only be considered in patients who are sensitive to penicillin or macrolide group of antibiotics). When use of antibiotics is really deemed necessary, fluoroquinolones should be avoided in patients with risk factors. Those with a history of fluoroquinolone-related tendinopathy should not be prescribed drugs of this class. We should also avoid co-prescription with steroid. If no better alternative is available, patients should be warned of this potential adverse effect and advised to stop the drug and seek medical advice if there are symptoms suggestive of tendinopathy. Athletes who are prescribed with fluoroquinolones should casting or operative repair. 
be advised to alter their training regimen (reduction in high-intensity and ballistic activities, decrease in total training volume) during the course of the antibiotics. ${ }^{14}$

\section{References}

1. Naranjo CA, Busto U, Sellers EM, et al. A method for estimating the probability of adverse drug reactions. Clin Pharmacol Ther 1981;30:239-45.

2. Bailey RR, Kirk JA, Peddie BA. Norfloxacin-induced rheumatic disease. N Z Med J 1983;96:590.

3. Corrao G, Zambon A, Bertù L, et al. Evidence of tendinitis provoked by fluoroquinolone treatment: a case control study. Drug Saf 2006;29:889-96.

4. van der Linden PD, Sturkenboom MC, Herings RM, Leufkens HG, Stricker BH. Fluoroquinolones and risk of Achilles tendon disorders: case-control study. BMJ 2002;324:1306-7.

5. Le Huec JC, Schaeverbeke T, Chauveaux D, Rivel J, Dehais J, Le Rebeller A. Epicondylitis after treatment with fluoroquinolone antibiotics. J Bone Joint Surg Br 1995;77:293-5.

6. Khaliq Y, Zhanel GG. Fluoroquinolone-associated tendinopathy: a critical review of the literature. Clin Infect Dis 2003;36:1404-10.
7. Liang VY, Ghearing GR, Zivkovic SA. Carpal tunnel syndrome after ciprofloxacin-induced tendinitis. J Clin Neuromuscul Dis 2010;11:165-6.

8. Schwald N, Debray-Meignan S. Suspected role of ofloxacin in a case of arthralgia, myalgia, and multiple tendinopathy. Rev Rhum Engl Ed 1999;66:419-21.

9. Tsai WC, Yang YM. Fluoroquinolone-associated tendinopathy. Chang Gung Med J 2011;34:461-7.

10. Wise BL, Peloquin C, Choi H, Lane NE, Zhang Y. Impact of age, sex, obesity, and steroid use on quinoloneassociated tendon disorders. Am J Med 2012;125:1228. e23-1228.e28.

11. Williams RJ 3rd, Attia E, Wickiewicz TL, Hannafin JA. The effect of ciprofloxacin on tendon, paratenon and capsular fibroblast metabolism. Am J Sports Med 2000;28:364-9.

12. Shakibaei M, Pfister K, Schwabe R, et al. Ultrastructure of Achilles tendons of rats treated with ofloxacin and fed a normal or magnesium-deficient diet. Antimicrob Agents Chemother 2000;44:261-6.

13. Sendzik J, Shakibaei M, Schäfer-Korting M, Stahlmann R Fluoroquinolones cause changes in extracellular matrix signalling proteins, metalloproteinases and caspase- 3 in cultured human tendon cells. Toxicology 2005;212:24-36.

14. Hal MM, FinnoffJT, Smith J. Musculoskeletal complications of fluoroquinolones: guidelines and precautions for usage in the athletic population. PM R 2011;3:132-42. 